\title{
CENTRALIDADE NO CLIENTE: DO DISCURSO PARA A AÇÃO
}

\author{
Por Sílvio Abrahão Laban Neto \\ Professor e Coordenador Geral dos Programas de MBA, INSPER - Instituto de Ensino e Pesquisa - São Paulo - SP, Brasil \\ silvioaln@insper.edu.br
}

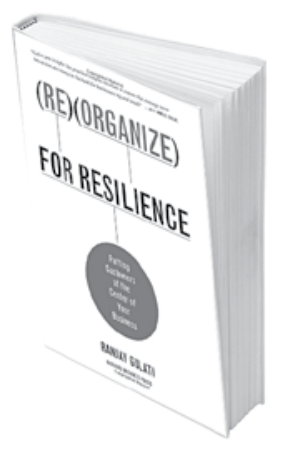

(RE) (ORGANIZE) FOR RESILENCE: PUTTING CUSTOMERS AT THE CENTER OF YOUR BUSINESS

De Ranjay Gulati. Boston: Harvard Business Press, 2010. 288 p.

Em seu livro Management: tasks, responsibilities, practices de 1973, Peter Drucker afirmou que o propósito final de qualquer organização deveria ser a satisfação dos clientes, construída com base em suas necessidades, realidades e valores. Muitos trabalhos subsequentes, principalmente na área de marketing, enfatizam a ideia de direcionar ações e decisões para o cliente. Trata-se de mais um desses conceitos simples, fáceis de apresentar, entender e incluir no discurso, porém de difícil e complexa execução. Essas dificuldades podem ser explicadas por diversos fatores externos e internos às organizações.

Os fatores ambientais externos, tais como a globalização, a redução das barreiras ao comércio entre os países, a rápida disseminação de informações e a "descoberta" dos mercados dos países emergentes e da população de baixa renda contribuem para um contexto cada vez mais compe- titivo, dinâmico e complexo, repleto de oportunidades e desafios. Dado esse contexto externo em constante mutação, as organizações começam a perceber a necessidade de aumentar sua capacidade de resposta e adaptação a clientes muito mais informados, conectados, poderosos, exigentes e com novas demandas.

Considerado por publicações como The Economist e pelo Financial Times como um dos poucos acadêmicos capazes de produzir trabalhos relevantes para a prática gerencial e com invejável produção e atuação acadêmica nas áreas de estratégia e organizações, o professor de origem indiana Ranjay Gulati, atualmente vinculado à Harvard Business School, busca oferecer em seu mais recente livro, (Re) (Organize) for Resilience, tanto para a academia quanto para a prática gerencial, um conjunto de ações a se considerar para que as organizações possam repensar suas estruturas e processos na direção de maior adaptação, foco e centralidade no cliente.

O livro, partindo do estudo de 12 empresas de diferentes setores, busca identificar os fatores que podem explicar seu sucesso, bem como oferece um conjunto de ações e recomendações para desenvolver estruturas organizacionais mais resilientes. Emprestado da física, o conceito de resiliência vem sendo empregado para caracterizar indivíduos, empresas e sistemas capazes de enfrentar situações limites e ajustar-se a elas, mantendo sua capacidade de produção e operação.

As notas e a bibliografia merecem destaque e refletem a dimensão e a multidisciplinaridade da pesquisa ao considerar autores como: Burt, Day, Deshpande, Christensen, Di Maggio, Drucker, Kotter, Kumar, March, Mintzberg, Prahalad, Simon, Uzzi e Weick.

A introdução, intitulada Resilience in Turbulent Markets, toma como pano de fundo a crise financeira global de 
2008/2009, introduz o conceito de resiliência e as empresas pesquisadas, conclamando as empresas a buscar uma abordagem de fora para dentro, ou seja, integrar o mercado em suas ações e abordagens, na mesma direção apontada por Patricia Seybold no livro Outside Innovation: How Your Customers Will Co-Design Your Company's Future, de 2006.

O capítulo 1, Building a Resilient Organisation, introduz a ideia das cinco alavancas que devem ser utilizadas na construção de uma organização mais resiliente, denominadas 5Cs: Coordination (Coordenação), Cooperation (Cooperação), Clout (Poder de decisão), Capabilities (Capacitação) e Connections (Conexões). Cada alavanca é objeto de um capítulo específico.

O capítulo dedicado à Coordenação identifica as principais barreiras à sua implantação e aponta ações, iniciativas e exemplos para superá-las. As principais barreiras, já abordadas pelo autor na Harvard Business Review, seriam a existência de silos organizacionais e as dificuldades de compartilhamento de informações e tarefas entre as áreas (The Quest for Customer Focus, abr. 2005; e Silo Busting, maio 2007).

A Cooperação implica adotar uma visão de processos orientados aos clientes e não internamente e pressupõe estabelecer uma estrutura de incentivos que estimule o compartilhamento de metas e objetivos. Além de alinhar incentivos, torna-se necessário recrutar, integrar e capacitar indivíduos orientados à cooperação. A cooperação, portanto, pressupõe a integração de pessoas, metas e propósitos comuns.

A terceira alavanca, Clout, traduzida como Poder de Decisão, implica delegar autoridade e poder para os colaboradores que lidam diretamente com os clientes, bem como eliminar barreiras que impeçam o desenvolvimento de ações voltadas para melhor servir aos clientes. As organizações, portanto, deveriam alterar sua estrutura de poder delegando poder e responsabilidade àqueles colaboradores mais próximos dos clientes. Trata-se de tema recorrente, que vem sendo abordado há décadas em publicações como: Momentos da Verdade, de Jean Carlzon (1987), e Programando o Futuro: o Trem da Linha Norte, de Karl Abrecht (1994).

A penúltima alavanca refere-se ao desenvolvimento de Capabilities, Competências, para preparar colaboradores generalistas para cuidar dos clientes, em parceria com os especialistas em produtos. O desenvolvimento dessas competências demanda superar os limites impostos pela estrutura organizacional e é alavancado pela exploração das redes informais. As redes sociais e suas implicações têm recebido significativa atenção e, nesse tópico, o professor Gulati integra seus trabalhos publicados em periódicos acadêmicos e em seu livro anterior: Managing Network Resources, de 2007.

O capítulo 6 aborda Conexões, parcerias e alianças que uma organização deve desenvolver com seus agentes externos para concentrar seu foco, aumentar sua agilidade ou adquirir competências e que enfrentam os mesmos desafios identificados na Coordenação e Cooperação. Um ponto interessante proposto pelo autor refere-se à necessidade de a organização repensar e redefinir suas atividades centrais, avaliando delegar a parceiros a execução de atividades periféricas. Reconhecese aqui as contribuições de autores como Gary Hamel, C. K. Prahalad e Charles Handy.

A conclusão descreve o processo de construção de uma organização mais resiliente e, portanto, mais centrada no cliente, como uma jornada tendo os 5Cs como orientação. No primeiro estágio, as organizações orientam suas ações à oferta e, portanto, de dentro para fora. No seguinte, reconhece-se a existência de diferenças entre os clientes e segmentá-los, mantendo-se a ênfase na oferta, é a solução adotada. Nesses dois estágios, Coordenação e Cooperação seriam suficientes, uma vez que não existiriam modificações estruturais na orientação da organização. O terceiro estágio consiste na oferta de soluções aos clientes e, por essa razão, as demais alavancas precisam ser acionadas. Aqui, as empresas reconhecem a necessidade de melhor compreender as demandas dos clientes e buscam oferecer-lhes não produtos, mas soluções aos seus problemas. O último estágio de uma organização resiliente e centrada no cliente é aquele em que a abordagem se dá de fora para dentro, ou seja, o cliente passa a ser parte integrante do processo de desenvolvimento da oferta.

O professor Gulati demonstra em seu livro a capacidade de integrar sua pesquisa a outros trabalhos relevantes, criando um quadro de referência de aplicabilidade prática, conceitualmente bem fundamentado para o contexto das empresas na atualidade.

Todavia, a aplicação do modelo dos 5Cs necessitaria ser investigada em contextos culturais e competitivos distintos daqueles enfrentados pelas empresas estudadas no livro. Todas as alavancas são fortemente influenciadas por elementos culturais e comportamentais que podem oferecem desafios adicionais. Estudos como, por exemplo, os de Hofstede, já apontaram as diferenças existentes na forma pela qual diferentes culturas interpretam elementos como poder, relacionamento e incerteza. Pesquisas realizadas no contexto brasileiro indicam que temas como coordenação, cooperação, relacionamento e poder assumem características distintas daquelas encontradas nos países em que são mais profundamente estudados. 